\title{
Metoda badania defektów elementów spawanych z wykorzystaniem algorytmu cyfrowego przetwarzania obrazów
}

\section{Method to examination of quality of welding elements, based on algorithm to digital picture analysis}

\section{Streszczenie}

W artykule przedstawiono nową metodę umożliwiającą ocenę jakości spawanych elementów w wyniku zastosowania oryginalnego algorytmu umożliwiającego komputerową analizę fotografii powierzchni elementu spawanego, celem identyfikacji występowania potencjalnych defektów. Podstawą działania algorytmu jest cyfrowe przetwarzanie obrazu z wykorzystaniem odpowiednio wybranych sekwencji filtrów. $\mathrm{Na}$ analizowanym obrazie zostają wyeksponowane cechy wskazujące miejsca występowania potencjalnych defektów.

\section{Wstęp}

Kontrola elementów spawanych wykonywana jest jedynie metodami nieniszczącymi. Do badań nieniszczących wykorzystywanych w ocenie konstrukcji spawanych zaliczamy [1]:

- badania elektromagnetyczne (metodę prądów wirowych i metodę magnetyczną),

- badania ultradźwiękowe (metody przenikania, echa i rezonansową),

- badania radiologiczne (metody radiograficzne, radioskopowe i radiometryczne),

- badania wizualne (prowadzone metodą pośrednią i bezpośrednią),

- badania penetracyjne (metody: barwna, fluorescencyjna i barwno-fluorescencyjna).

$\mathrm{Z}$ wymienionych powyżej metod badań jedynie badania wizualne prowadzone metodą bezpośrednią nie wymagają użycia dodatkowych urządzeń lub

Dr inż. Grzegorz Owczarek, dr inż. Grzegorz Gralewicz - Centralny Instytut Ochrony Pracy, Państwowy Instytut Badawczy, Warszawa.

\section{Abstract}

This article presents the new method to assess quality of welding elements. This method use the original algorithm to computer analysis of the picture of welded element surface to identify potential defects. Digital analysis of pictures with suitable sequence of filters is a base of operation of this algorithm. The features which indicated regions of potential defects are distinguished on the picture. przyrządów zewnętrznych. Wymagany jest jedynie dobry wzrok i odpowiednie (min. ok. 400 Ix) natężenie oświetlenia. Dla osób przeprowadzających badania wizualne konstrukcji spawanych przeprowadza się test widzenia polegający na badaniu ostrości widzenia oraz rozpoznawania barw [2]. Osoby te muszą rozpoznawać i różnicować kontrast między barwami lub odcieniami szarości stosowanymi w metodzie badań nieniszczących określonych przez pracodawcę. W niniejszym artykule przedstawiono metodę pozwalającą na komputerową analizę fotografii powierzchni elementu spawanego, celem identyfikacji występowania defektów.

\section{Założenia do metody}

Algorytm do cyfrowego przetwarzania obrazów powierzchni spawanych elementów obejmuje cztery podstawowe etapy:

- wprowadzenie obrazu wejściowego (przedstawiającego powierzchnię spawanego elementu) do programu realizującego algorytm cyfrowego przetwarzania obrazu; 


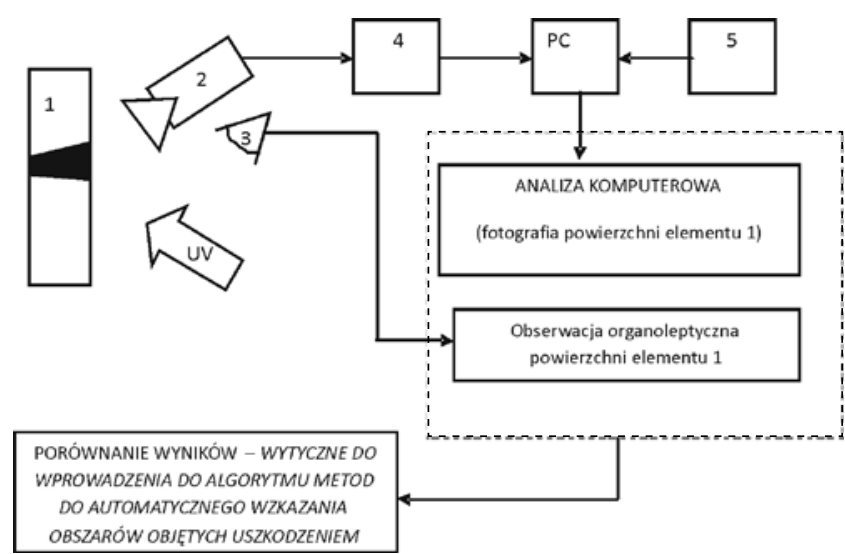

Rys. 1. Schemat przeprowadzenia analizy defektoskopowej: 1 - próbka elementu spawanego, UV - źródło promieniowania UV do oświetlenia badanej próbki, 2 - kamera, 3 - obserwacja wzrokowa, 4 - zdjęcie elementu spawanego, PC - komputer, 5 - program do wykrywania defektów elementów spawanych

Fig. 1. Diagram of defectoscopy analysis $1-$ sample of welding element, UV - UV radiation source to expose tested sample 2 - camera, 3 - eyes analysis, 4 - picture of welded element, PC - computer, 5 - software to detect defects test of welded elements

- cyfrowe przetwarzanie obrazu;

- wskazanie na analizowanym obrazie miejsc wystąpienia potencjalnych defektów;

- archiwizację danych.

Oprogramowanie jest przeznaczone do analizy obrazów otrzymanych z kamery cyfrowej dla określenia miejsca, poddanych analizie defektoskopowej przeprowadzonej $\mathrm{np}$. metodą penetracyjną, zgodnie ze schematem przedstawionym na rysunku 1.

Ujawnienie obszaru występowania wady może być realizowane na dwa zasadnicze sposoby. Pierwsze miejsce, w którym występuje wada, można określić znacznikiem np. w postaci okręgu o średnicy odpowiadającej wielkości uszkodzonego miejsca. Drugi sposób polega na wypełnieniu pola zdefektowanego obszaru kolorem. Oba sposoby umożliwiają wskazanie uszkodzonego miejsca za pomocą znacznika graficznego. W trakcie opracowania oprogramowania analizowano

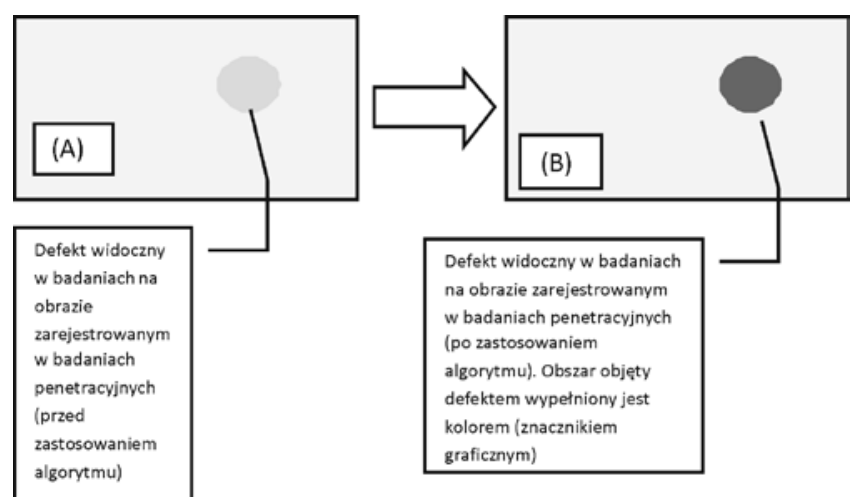

Rys. 2. Schematyczne przedstawienie zadania, jakie spełnia algorytm do wykrywania defektów elementów spawanych: (A) - obraz przed zastosowaniem algorytmu, (B) - obraz po zastosowaniu algorytmu

Fig. 2. Diagram of the task of algorithm for detect defects of welded elements: $(A)$ - the picture before analysis, $(B)$ - the picture after analysis

argumenty za i przeciw wprowadzeniu jednego z przedstawionych powyżej sposobów miejsca występowania defektu. Wynik tej analizy przedstawiono w tablicy I.

W oprogramowaniu do określania cech obrazu w układzie defektoskopu zaimplementowano znacznik wypełniający pole. Schemat działania algorytmu do badania defektów elementów spawanych przedstawiono na rysunku 2.

\section{Oprogramowanie do badania defektów elementów spawanych}

Oprogramowanie do badania defektów elementów spawanych opracowano z wykorzystaniem następują-

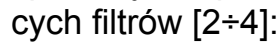

- wyostrzanie,

- desaturacja,

- filtr gradientowy z programowaną maską,

- progowanie,

- sumowanie obrazu wynikowego z obrazem otrzymanym w wyniku przetwarzania.

Tablica I. Sposoby wprowadzenia znacznika graficznego do analizowanego obrazu

Table I. Method of implementation of graphic sign to analyzed picture

\begin{tabular}{|c|l|l|}
\hline Rodzaj znacznika & \multicolumn{1}{|c|}{ Za } & \multicolumn{1}{|c|}{ Przeciw } \\
\hline Znacznik w postaci okręgu & $\begin{array}{l}\text { Pozostawienie niezmienionego obrazu } \\
\text { miejsc zdefektowanych (brak ich wypeł- } \\
\text { nienia) }\end{array}$ & $\begin{array}{l}\text { Wprowadzenie dużej ilości obszarów w przypadku pojawia- } \\
\text { nia się artefaktów; } \\
\text { Przesłonięcie innych, nieobjętych defektem, elementów } \\
\text { obrazu konturami znacznika; } \\
\text { Konieczność wyliczenia promienia znacznika w odniesieniu } \\
\text { do kształtu i wymiarów zdefektowanego obszaru }\end{array}$ \\
\hline Znacznik wypełniający pole & $\begin{array}{l}\text { Ograniczenie obszaru powierzchni } \\
\text { znacznika do miejsca faktycznie zdefek- } \\
\text { towanego; } \\
\text { Możliwość łatwej identyfikacji artefaktów }\end{array}$ & Wypełnienie na obrazie miejsca objętego defektem \\
\hline
\end{tabular}


Tablica II. Rodzaje filtrów zaimplementowane w oprogramowaniu do badania defektów elementów spawanych Table II. Type of filters implemented to algorithm for detect defects of welded elements

\begin{tabular}{|c|c|c|c|}
\hline \multicolumn{2}{|c|}{ Nazwa filtru } & \multirow{2}{*}{$\frac{\text { Symbol }}{\mathbf{F}_{\mathrm{sN}}}$} & Opis \\
\hline \multirow{4}{*}{ Wyostrzanie (sharpen) } & Normalny (normal) & & \multirow{4}{*}{ Działanie filtru powoduje wyostrzanie krawędzi } \\
\hline & $\mathrm{H} 1$ & $\mathbf{F}_{\mathrm{SNH} 1}$ & \\
\hline & $\mathrm{H} 2$ & $\mathbf{F}_{\mathrm{SNH} 2}$ & \\
\hline & $\mathrm{H} 3$ & $\mathbf{F}_{\mathrm{SNH} 1}$ & \\
\hline \multirow{2}{*}{ Desaturacja (desaturation) } & Normalny (normal) & $F_{\mathrm{DN}}$ & \multirow{2}{*}{$\begin{array}{l}\text { Zmiana obrazu barwnego na czarno-biały (odcienie } \\
\text { szarości) }\end{array}$} \\
\hline & Proporcjonalny (with proportion) & $F_{\text {DNP }}$ & \\
\hline \multirow{8}{*}{ Gradient (gradient) } & Wschód (east) & $\mathbf{F}_{\mathrm{GE}}$ & \multirow{8}{*}{$\begin{array}{l}\text { Wyróżniają krawędzie obrazu w zgodnej z kierunkiem } \\
\text { części obrazu, a nie tak jak w przypadku filtrów przesu- } \\
\text { wających równo w całym obrazie. Kierunki na obrazie } \\
\text { określane są tak, jak kierunki geograficzne. }\end{array}$} \\
\hline & Południowy wschód (south east) & $\mathbf{F}_{\mathrm{GSE}}$ & \\
\hline & Południe (south) & $\mathbf{F}_{\mathrm{GS}}$ & \\
\hline & Południowy zachód (south west) & $\mathbf{F}_{\mathrm{Gsw}}$ & \\
\hline & Zachód (west) & $F_{\text {GNW }}$ & \\
\hline & Północny zachód (north west) & $\mathbf{F}_{\mathrm{GE}}$ & \\
\hline & Północ (north) & $\mathbf{F}_{\mathrm{GN}}$ & \\
\hline & Północny wschód (north east) & $\mathbf{F}_{\mathrm{GNE}}$ & \\
\hline Progowanie (tresholding) & Progowanie <wartość progu $>$ & $\left.\mathbf{F}_{\mathrm{P}}^{*}\right)$ & $\begin{array}{l}\text { Zadanie progu o takiej wartości, aby w wyniku przepro- } \\
\text { wadzenia tej operacji piksele o wartościach luminancji } \\
\text { poniżej progu były kwalifikowane do jednej grupy, a pik- } \\
\text { sele poniżej wartości progu do drugiej grupy. }\end{array}$ \\
\hline Mediana (median) & - & $\mathbf{F}_{\mathbf{M}}$ & Usunięcie szumów z obrazu \\
\hline $\begin{array}{l}\text { Sumowanie obrazów } \\
\text { (sum with oryginal) }\end{array}$ & - & $\mathbf{F}_{\Sigma}$ & Nałożenie znacznika na obraz wejściowy \\
\hline
\end{tabular}

Opracowane oprogramowanie pozwala na zastosowanie dowolnie wybranego filtru, w dowolnej kolejności i dowolną ilość razy. Oznacza to, że obraz cyfrowy badanej powierzchni może być wielokrotnie analizowany z wykorzystaniem dowolnie opracowanej sekwencji filtrów. Każdemu z zaimplementowanych filtrów przypisano następujące symbole (tabl. II).

Sekwencje filtrów mogą więc przedstawiać się następująco:

Przykład 1: $\mathrm{F}_{\mathrm{SN}} / \mathrm{F}_{\mathrm{DN}} / \mathrm{F}_{\mathrm{GN}} / \mathrm{F}_{\mathrm{P} 128} / \mathrm{F}_{\mathrm{M}} / \mathrm{F}_{\Sigma}$

Przykład 2: $F_{\mathrm{SN}} / \mathrm{F}_{\mathrm{M}} / \mathrm{F}_{\mathrm{DN}} / \mathrm{F}_{\mathrm{SN}} / \mathrm{F}_{\mathrm{GN}} / \mathrm{F}_{\mathrm{P} 56} / \mathrm{F}_{\mathrm{M}} / \mathrm{F}_{\Sigma}$

Tak utworzone sekwencje filtrów można zapisać, tworząc bibliotekę sekwencji filtrów. Każdy kolejny obraz przeznaczony do analizy można poddać obróbce poprzez sekwencje utworzonych filtrów zapisanych w bibliotece lub zastosowanie dowolnego innego filtra/sekwencji filtrów.

Poniżej zaprezentowano przykład analizy obrazu przedstawiającego pęknięcie spoiny złącza czołowego wykonanej metodą spawania łukowego. Zastosowano następującą sekwencje filtrów:

$$
\mathrm{F}_{\mathrm{SN}} / \mathrm{F}_{\mathrm{DN}} / \mathrm{F}_{\mathrm{GN}} / \mathrm{F}_{\mathrm{P} 128} / \mathrm{F}_{\mathrm{M}} / \mathrm{F}_{\Sigma}
$$

Wybór taki był podyktowany następującymi względami:

- w pierwszym etapie wyostrzono krawędzie na całej analizowanej powierzchni;

- następnie - $z$ uwagi na zastosowanie progowania - dokonano zamiany obrazu z barwnego na czarnobiały;

- w celu kierunkowego wyróżnienia krawędzi obrazu zastosowano filtr gradientowy;

- dokonano progowania, aby oddzielić wyróżnione piksele obrazu (miejsca występowania potencjalnych defektów);

- obserwując obraz po progowaniu zauważono szumy (miejsca, które mogą stanowić artefakty); zastosowanie filtru medianowego spowodowało usunięcie szumów.

Kolejne etapy analizy zaprezentowano na rysunku 3, gdzie przedstawiono wprowadzony do analizy obraz wejściowy, na którym widoczne są dwie próbki elementów spawanych. Spoina spawalnicza próbki po prawej stronie obrazu jest pęknięta. Rysunek przedstawia również obrazy po kolejnych etapach analizy (po zastosowaniu określonego w sekwencji filtra). Miejsca pęknięć zostały wypełnione na analizowanym obrazie znacznikiem (kolor czerwony). 


\section{Zrzut ekranu, na którym wyświetlany jest wczytany obraz do analizy defektoskopowej}

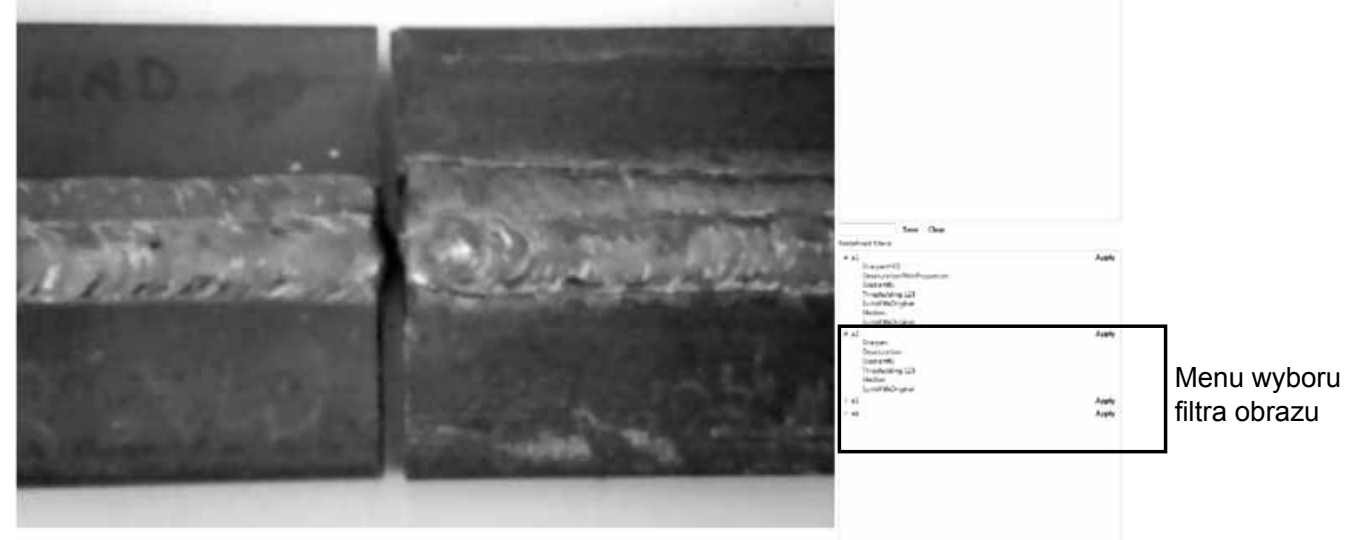

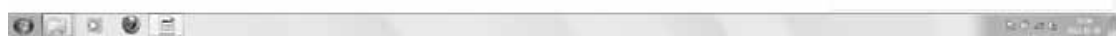

Obrazy uzyskane po zastosowaniu wybranych filtrów:

- Wyostrzenie (Sharpen)

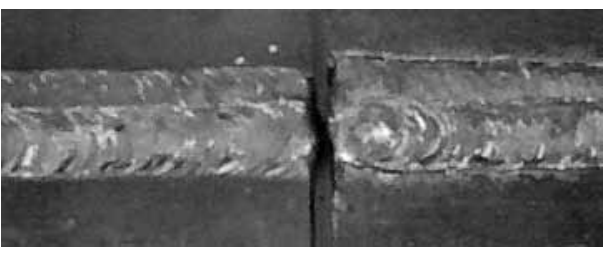

- Gradient N (Gradient N)

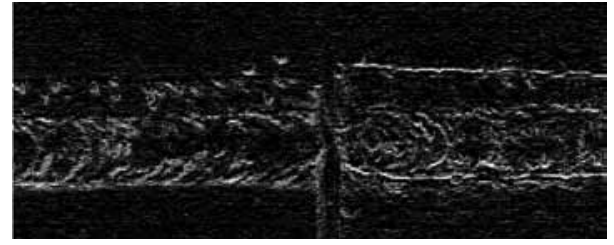

- Mediana (Median)

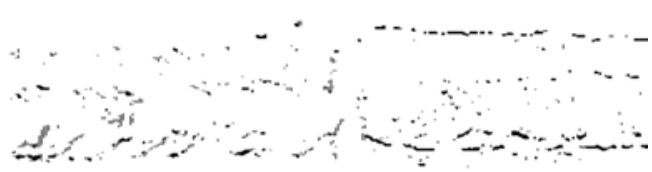

Rys. 3. Obraz elementu spawanego poddany analizie

Fig. 3. Picture of the analysed welded element
- Desaturacja (Desaturation)

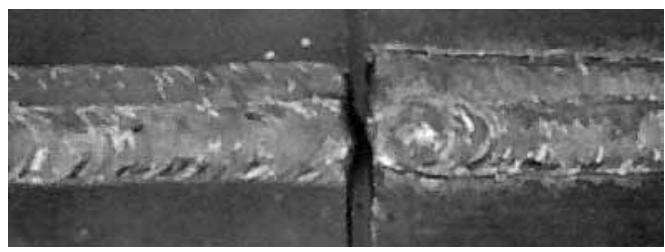

- Progowanie 128 (Tresholding 128)

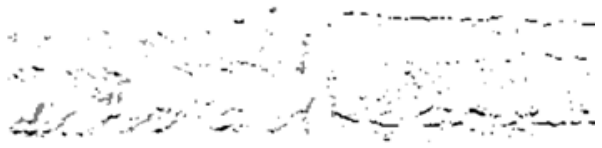

- Sumowanie obrazów (Sum with oryginal)

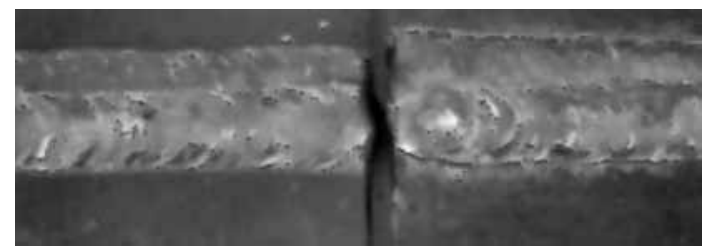

\section{Wnioski}

Metoda badania defektów elementów spawanych $\mathrm{z}$ wykorzystaniem algorytmu cyfrowego przetwarzania obrazów pozwala na wskazanie miejsc występowania potencjalnych defektów przez wprowadzenie na analizowany obraz kolorowego znacznika. Wyróżnienie miejsca występowania potencjalnego defektu może być pomocne w ocenie defektoskopowej dla osób z wadą wzroku (np. zaburzenia w rozpoznawaniu barw). Zastosowanie opisanej metody pozwala również na wnikliwą analizę dokumentacji fotograficznej elementów spawanych. Fotografie przedstawiające powierzchnie spawanych elementów poddane cyfrowej obróbce obrazu - z wykorzystaniem zaprezentowanego algorytmu - niezależnie od czasu ich wykonania oraz formatu wykonanego zdjęcia mogą zostać wprowadzone do programu i poddane szczegółowej analizie, której zadaniem jest wskazanie i/lub uwydatnienie takich cech obrazu, które mogą świadczyć o występowaniu defektów. 


\section{Literatura}

[1] Deputat J., Mackiewicz S., Szelążek J.: Problemy i techniki nieniszczących badań materiałów - wybrane wykłady, Wydawnictwo GAMMA, 2007.

[2] PN-EN 473: 2008 Badania nieniszczace - Kwalifikacja i certyfikacja personelu badań nieniszczących - Zasady ogólne.
[3] Smołka J.: Rozprawa doktorska, Adaptacyjny system wspomagający usuwanie nadsegmentacji w obrazach poddanych transformacji wododziałowej, Politechnika Śląska, Gliwice, 2010

[4] Malina M., Smiatacz M.: Cyfrowe przetwarzanie obrazów, Warszawa 2008

[5] Bal A.: Ważona lokalna metoda poprawy kontrastu obrazów cyfrowych, Przegląd telekomunikacyjny, 6/2008.

Publikacja opracowana na podstawie wyników uzyskanych w ramach II etapu programu wieloletniego pn. „Poprawa bezpieczeństwa i warunków pracy”, sfinansowanego w latach 2011-2013 w zakresie badań naukowych i prac rozwojowych przez Ministerstwo Pracy i Polityki Społecznej. Koordynator programu: Centralny Instytut Ochrony Pracy - Państwowy Instytut Badawczy.

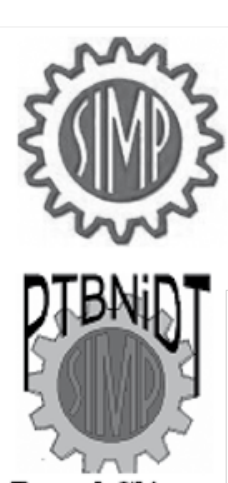

Zarzạd Glówny

$$
\begin{gathered}
\text { BIURO } \\
\text { KONFERENCJI: } \\
\text { Ośrodek Doskonalenia Kadr } \\
\text { SIMP } \\
\text { ul. Sabały 11a } \\
\text { 71-341 Szczecin } \\
\text { e-mail: } \\
\text { odk.simp@neostrada.pl } \\
\text { tel/fax } \\
\text { (+48 91) 442 00 07 } \\
\text { www.odksimp- } \\
\text { szczecin.neostrada.pl }
\end{gathered}
$$
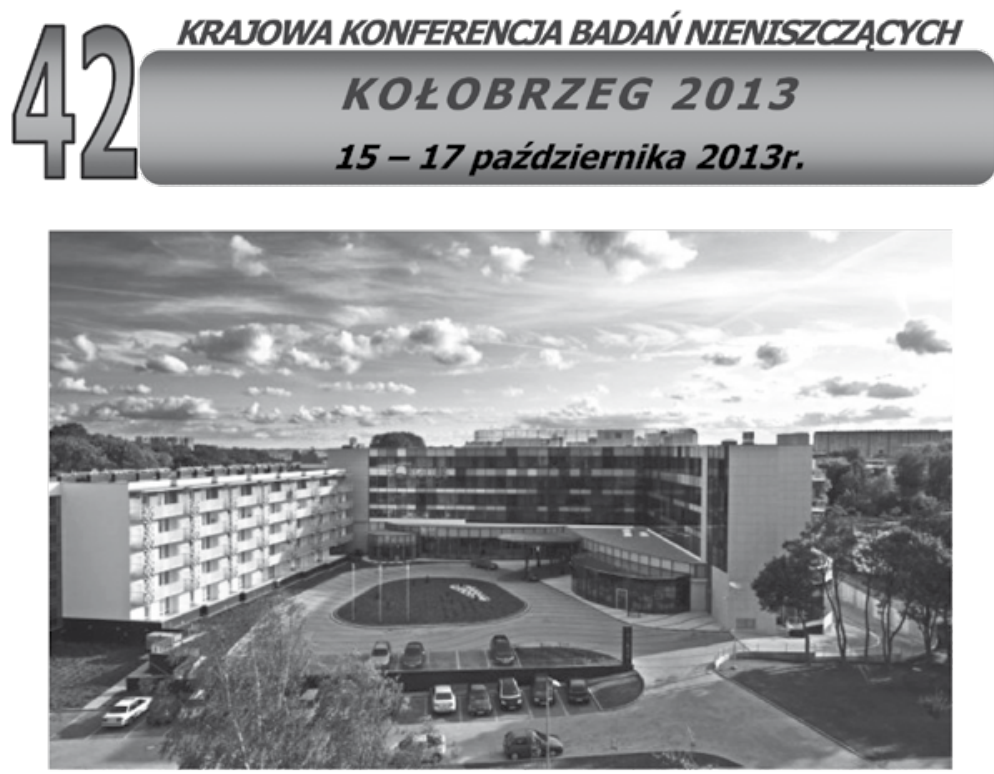

\section{Z a p rasza m y}

do zgłaszania się i udziału w

\section{KRAJOWEJ KONFERENCJI BADAŃ NIENISZCZĄCYCH KOEOBRZEG 2013}

pt. „Racjonalna diagnostyka obiektów technicznych podstawą remontów, modernizacji, gwarancji i procedur ubezpieczeniowych"

która odbędzie się w dniach 15 - 17 października 2013r.

Miejsce konferencii

Hotel „AQUARIUS” SPA, ul. J. Kasprowicza 24, 78-100 Kołobrzeg

\section{Zakres tematvczno-programowy konferencii}

\section{SESJE PLENARNE oraZ WYSTAWA APARATURY i WYPOSAŻENIA}

- badania nieniszczące w przemyśle - produkcja i eksploatacja;

- badania nieniszczące w pracach naukowych i projektowaniu;

- diagnostyka i ocena stanu technicznego obiektów przemysłowych;

- znaczenie diagnostyki dla ryzyka awarii oraz procedur ubezpieczeniowych;

- badania nieniszczące w innych, nieprzemysłowych obszarach;

- aparatura, urządzenia, oprzyrządowanie i materiały do badań NDT;

- kierunki rozwoju, metodyka i normalizacja badań nieniszczących;

- szkolenie i certyfikacja personelu oraz akredytacja laboratoriów.

Rejestracja zgłoszeń uczestników i wystawców do 10 września 2013r.

Nadsyłanie pełnych tekstów referatów i streszczeń do 31 sierpnia $2013 \mathrm{r}$ 